\title{
Automated Water Managemenrt System (WMS)
}

\author{
Rakib Ahemed ${ }^{a}$, Mahfida Amjad b,* \\ ${ }^{a}$ B. Sc student of CSE, Stamford University Bangladesh, Bangladesh \\ ${ }^{b}$ Senior Lecturer, Department of CSE, Stamford University Bangladesh, Bangladesh
}

Received: 17 November 2018; Accepted: 15 February 2019; Published: 08 May 2019

\begin{abstract}
Water automation is all about controlling, monitoring and even billing of water usage in different places like hotel, house, irrigation land and industry. The researchers done water automation based on different purposes using different types of hardware and technologies. This paper develops Automated Water Management System (WMS) which can monitor water tank by measuring the water flow, water level, water temperature, cut ON/OFF water supply and send notifications to the user through mobile messaging. All of the things are connected through an android application that is much more efficient and easier to control the whole process.
\end{abstract}

Index Terms: Water Automation, Water Management System, Mobile Messaging, Mobile Application, Android Application.

(C) 2019 Published by MECS Publisher. Selection and/or peer review under responsibility of the Research Association of Modern Education and Computer Science.

\section{Introduction}

In this modern world we live in, the mobile application has brought many benefits to individuals, organizations and industries. With the help of the internet it is also possible to make a better water monitoring system for monitoring water pump, making water surface organize to take action for any type of problem, solve and disturbing water easily and even for billing.

The automatic use of water can be called water automation which is a process to ensure the proper use of water and reduce the human effort. It is used for different purposes such as irrigation in the agricultural land, water pump controlling, water usage monitoring, billing of water usage etc. in different places like household, agricultural land, industry, hotel etc [1].

In manual system of water tank the user needs to present at the water pump to turn it ON and OFF. On the other hand, an automated system uses android application to turn the water pump ON and OFF [1]. Researchers

\footnotetext{
* Corresponding author. Tel.: +880 1955368025

E-mail address: mahfidaamjad@stamforduniversity.edu.bd
} 
have implemented several water automation systems $[2,3,4,5,6,7,8,9,10,11,12]$ based on water pump controller, water level detection, water billing with detection and control of water leakage by using different types of hardware and technology.

Automated Water Management System (WMS) is an automated system for water management to make daily life easy and efficient through the use of mobile application. It can control water distribution and take action for any current situation which created in the water tank according to the water surface by using sensors and data results. WMS is providing a system which can observe water tank and take action if water surface is high or low, it can auto generate to on/off motor and also if any user wants to change water temperature then he/she can also do it. When a user used his/her maximum rate of water then it must be cut off his/her line automatically. By using mobile messaging user get notifications before cut off his/her line and also show how much water he/she already used.

The rest of this paper is organized as follows. Section 2 describes the literature review, Section 3 illustrated the system architecture and design and Section 4 is about discussion and future work. This paper will be ended in section 5 .

\section{Related Work}

This section contains the brief discussion of some recent works of water automation. There are some existing works related to automation of water pump discussed in [1].

A model is presented in [2] which can collect water expense from a customer and detect the leakage in the water distribution system. The advantage of this model is that it can reduce the periodic tours of providers to each physical location to read each meter. Another advantage is that the bill of water usage can give based on the near real-time expense from the previous expense. Detecting leak supports to save water resources and energy and also reduce the cost.

The paper [3] proposes a water monitoring system by using an automatic overflow control circuit unit. The proposal is designed from the perspective of monitoring the flow of water into the tanks automatically and from the perspective of setting as per the user demands using a Mobile Application. The advantages of the system are the conservation of water resource, reduction of the manual attempt, and time to time changes over the situation of water storage with the help of sensors.

A model of variable rate microcontroller based automated irrigation system has been proposed in [4]. Solar power has used as the only source of power to control the entire process. Without visiting the agricultural land, farmers can find the information about the moisture level. Farmers can control the water pump based on the moisture level by sending a message from his/her cellular phone. Even when the farmers are away, the automated irrigation system always confirms the exact level of water in the agricultural lands.

A monitoring and control system for the IoT in the water supply and sewerage utilities has been described in [5]. It describes Hitachi's Internet of Things gateway that utilize operational technology data on the Internet of Things platform, optical fiber sensing as well as image analysis and voice recognition.

An IoT based water monitoring system [6] is developed using the sensors like $\mathrm{pH}$, Turbidity \& Ultrasonic sensor which are connected with different microcontrollers like Arduino Uno \& Node MCU. And three sensors $\mathrm{pH}$, turbidity, Ultrasonic are connected with Arduino Uno \& ESP 8266 to sending data to the cloud. One ultrasonic sensor is connected with the Node MCU. In Node MCU is connected with an ultrasonic sensor. The water level is shown by graph. The graph is plotted by using sensor data. This sensor data is sent to the cloud (Thing speak) using Node MCU and Wi-Fi module.

In [7] a water level monitoring system using IoT uses containers, where the ultrasonic sensors placed over the containers to detect the liquid level and compare it with the container's depth. The system makes use of AVR family microcontroller, Raspberry Pi, LCD screen, Wi-Fi modem for sending data and a buzzer. A $12 \mathrm{~V}$ transformer is used for power supply in this system. The LCD screen is used to display the status of the level of liquid in the containers. The liquid level is highlighted as colored to show the level of liquid present in the container with the help of a web page to the user. The buzzer starts ringing when the set limit of the liquid is 
crossed.

A water level monitoring system is developed in [8] where the system is integrated with a GSM module to alert the person-in-charge through Short Message Service (SMS). The water level is monitored and its data sent through SMS to the intended technician mobile's phone upon reaching the critical level.

A water level detection technique for water pump controller by using smart phones is described in [9]. A basic model of an android based application is proposed by which water pumps can be turned ON and OFF with the help of wireless radio transmitters and Wi-Fi router. The android app can run in Android OS version up to 6.0.1, i.e. Android Marshmallow. The paper briefly shows the connections between the required equipment's.

An automated system is described in [10] where a farmer can control the motor and irrigation process with the help of an android application. The automated control system uses microcontroller and Bluetooth Devices. The commands are sent to the receiver to control the movement of the seeding device either to move forward or backward using android application and the irrigation pump either to on or off. But in there is no presence of any interface of the android application.

In [11] it gives a description of monitoring water usage with the help of ultrasonic sensor. The water level is monitored and the data is sent to Server with the help of Wi-Fi module. The admin is notified through SMS when the motor pump starts and stops. The users would be able to see their water usage using android application. If there is any leakage or the member is not at home and the tap is left open, the water flow can be cut-off with the help of solenoid valve which can be operated from the android application.

An irrigation system is described in [12] using android application. The farmers can see the electricity status, motor status \& motor condition using the android mobile application. This mobile application helps to set the timer for starting the motor to the certain time.

A smart water quality monitoring system using IoT and remote sensing technology has been described in [13]. In this system GSM technology has been used to send alarm based on reference parameters of water from different water sources to the ultimate user for taking immediate action to ensure water quality.

An automated water usage monitoring system [14] describes a way of controlling the wastage of water at home or industries by means of wireless sensor nodes. It uses internet of things (IoT) to continuously monitor and track water usage via the wireless sensor nodes. Server collects the data through Wi-Fi/LAN to process and track usage and wastage of water. When water is used at excess it is indicated and an alert is sent to the user. The user can continuously keep a track of the water usage through a mobile or laptop with an internet connection.

A water quality monitoring system is presented in [15] which can be used by residential areas. This system uses PH sensor and TDS meter for measuring the water quality parameters. It also uses machine learning algorithm K-Means clustering for predicting the quality of water based on trained data set from different water samples. It has been implemented using Arduino Uno, Raspberry Pi3.

\section{System Architecture and Design}

This section will describe the developed WMS system in terms of system requirements, hardware implementation and design of mobile application.

\subsection{System Requirements}

The system requirements for WMS can be divided into two categories, one is hardware and two is software for mobile application. These are discussed in the following subsections-

\subsubsection{Hardware Requirements}

The hardware requirements for WMS are the followings- 


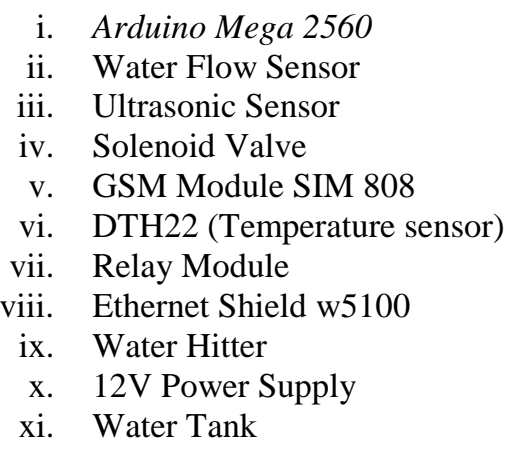

The system architecture of WMS is shown in Fig. 1.

\subsubsection{Software Requirements}

The software requirements for mobile application of WMS are the followings-
i. Android Studio
ii. Arduino IDE
iii. My SQL

\subsection{Hardware Implementation}

The hardware part of WMS helps to prevent overflow of water from the water tank and to avoid the situation of being the tank empty. When water level is lower than the limit, the pump will automatically ON. On the other hand, if the water level reached the top of the limit, then the pump will automatically turn OFF. WMS has set a limit for pump switching ON and OFF. It has a sonar pump at the top of the water tank which gives the measurement of water level.

The hardware implementation of WMS is shown in Fig. 2 which has been done for the following purposes-

\subsubsection{Smart Controlling of Water}

Smart controlling of water in WMS shown in Fig. 3 means that it can prevent overflow from the water tank and also avoid the situation of being the tank empty. When water level is lower than the limit, the pump will automatically turns ON. On the other hand, if the water level reached the top of the limit, then the pump will automatically turns OFF. This system has set a limit for pump switching ON and OFF. There is a sonar pump at the top of the water tank which will give the measurement of water level. There is an estimated limit for the user of water usages, if the user crosses the limit this system will automatically turn OFF water supply of that flat using solenoid valve.

\subsubsection{Automatic Water Heating}

WMS uses temperature sensor for automatic water heating which is shown in Fig. 4. If the water temperature is below the limit, water heater will be automatically $\mathrm{ON}$ and it will heat the water to expected temperature. The heater will turn OFF automatically after reaching the fixed temperature. 


\subsubsection{Monitoring and Controlling Flow Rate of Water}

In Fig. 5 for monitoring and controlling flow rate of water WMS uses a water flow sensor to the water supply line of a flat, which will give the value of total usages of water of that flat. Flat members can see the water usages through the android application. This system can set usage limit for every flat. If the water usage of any flat exceeds the limit the system will automatically turn OFF the water supply.

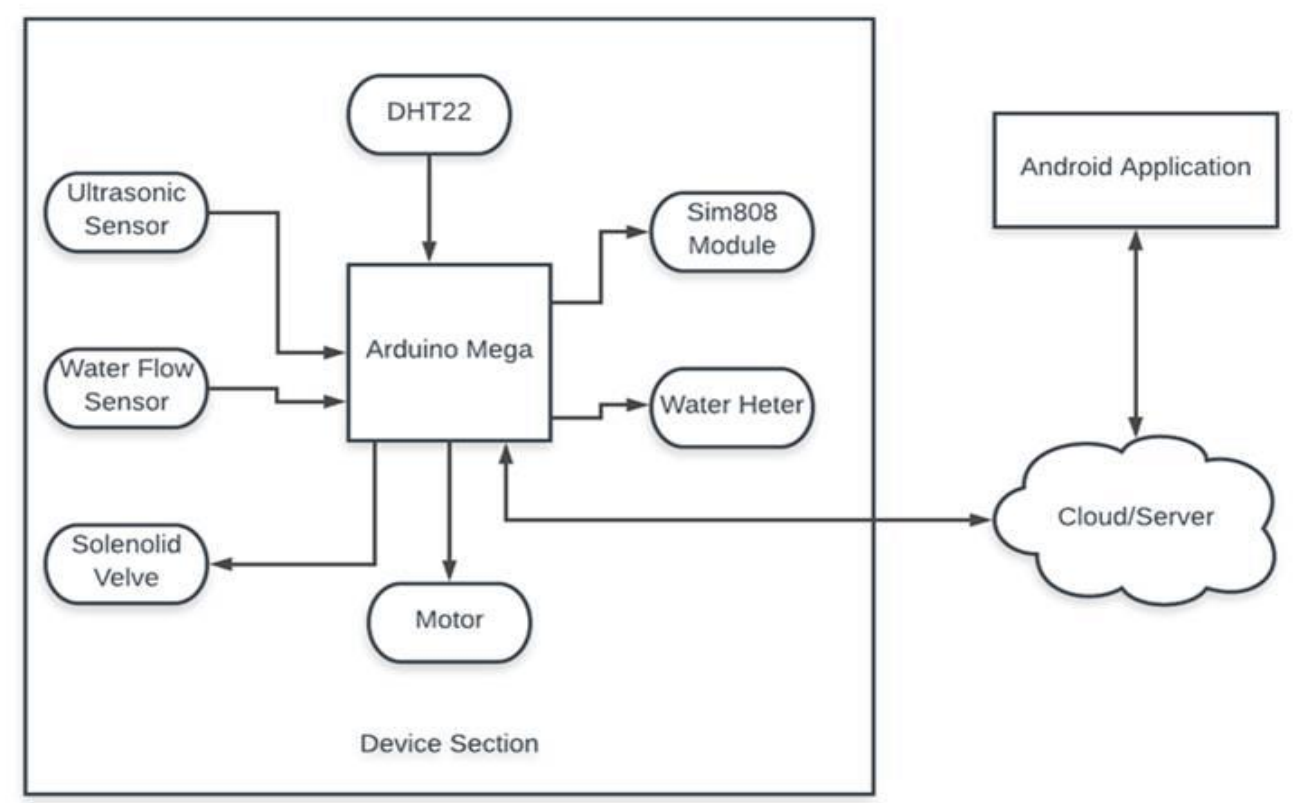

Fig.1. System Architecture of WMS

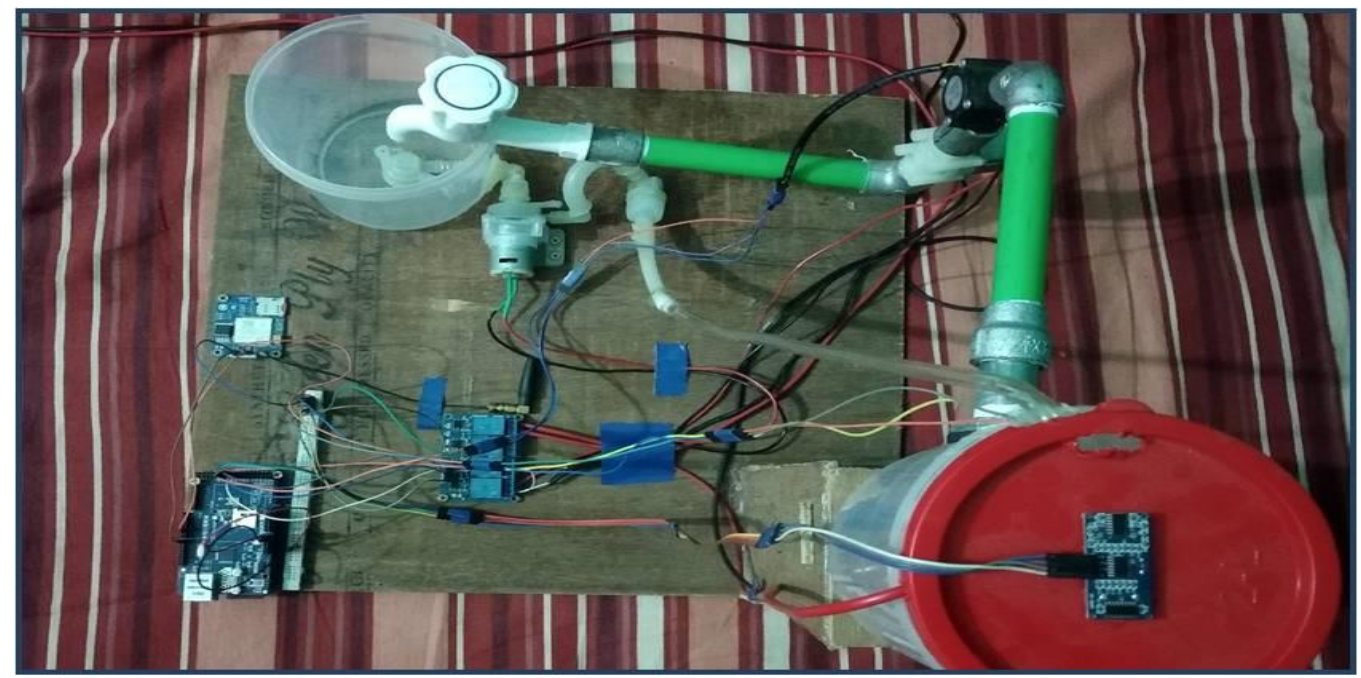

Fig.2. Hardware Implementation 


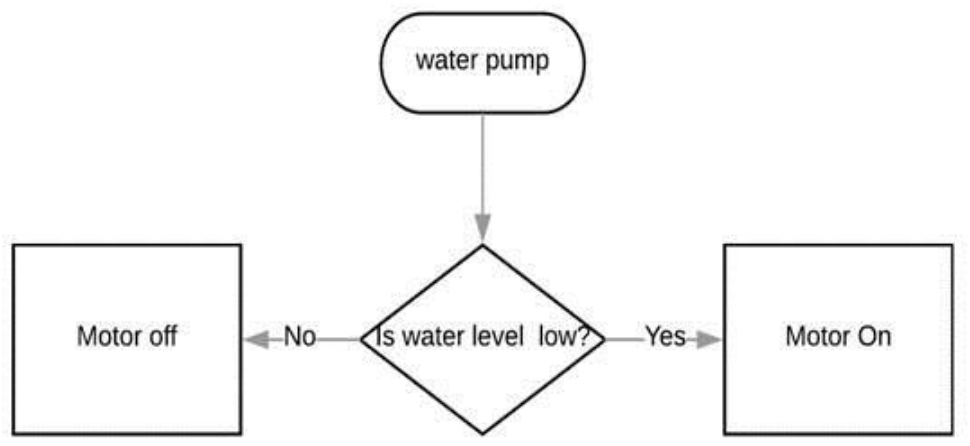

Fig.3. Flowchart for Smart Controlling of Water

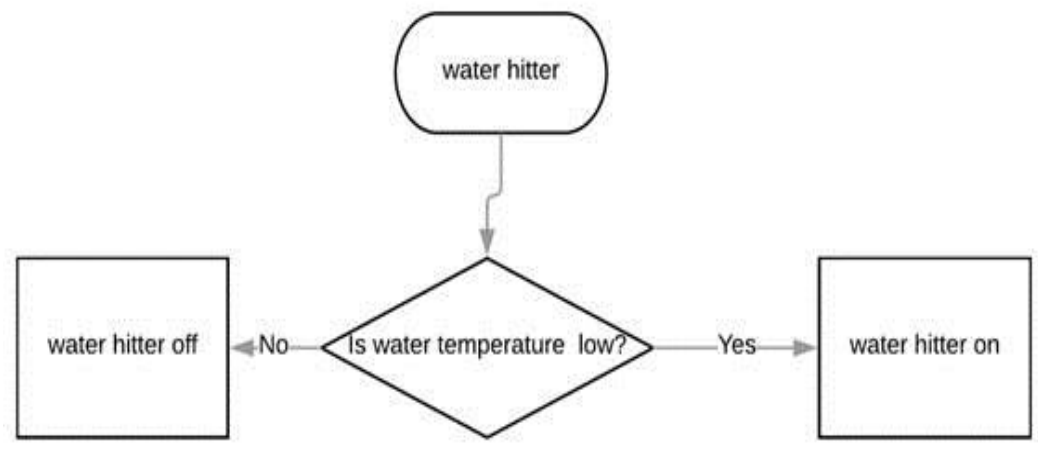

Fig.4. Flowchart of Automatic Water Heating

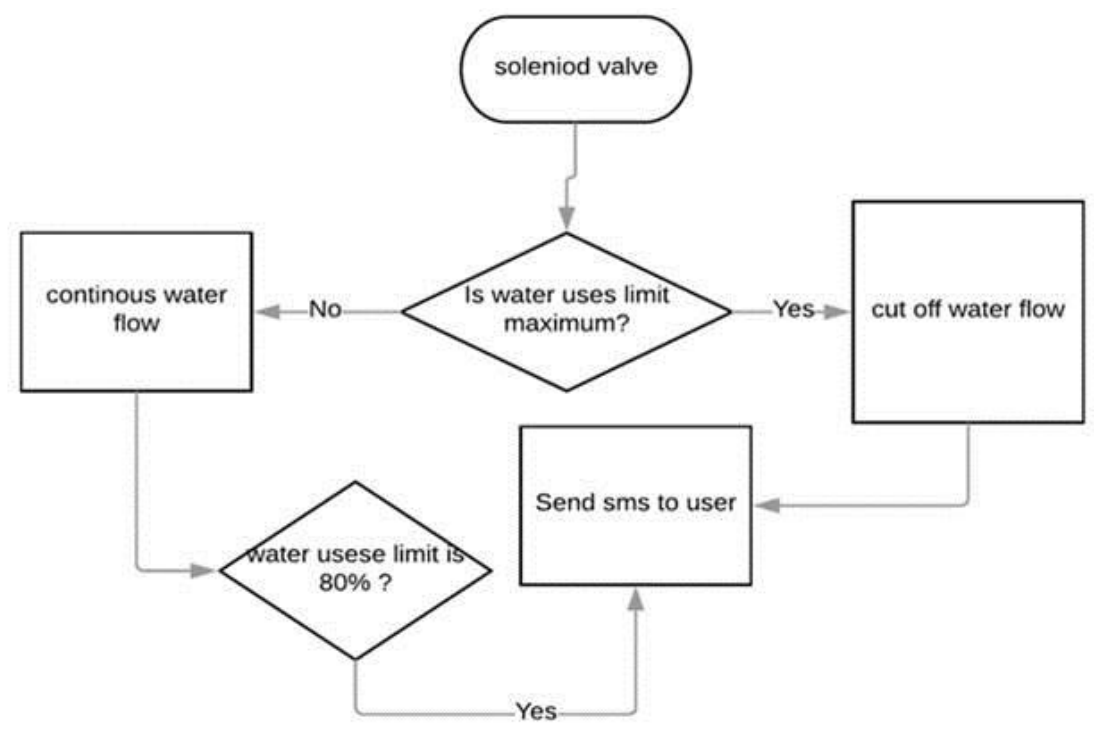

Fig.5. Flowchart for Monitoring and Controlling Flow Rate of Water 


\subsection{Design of Mobile Application}

WMS has a feature to monitor and control the water pump through the android application, if building owner wants to turn the water pump ON/OFF, he can do it through the android application. It has two switches in this application, one for solenoid valve and other is for water pump. The system divides into two part one is Register and another is Login. The application can be divided into two parts, one is registration and login and another is interface for water management.

\subsubsection{Registration and Login}

This feature is only for the admin who can register the user. After registration a user can access the system. Login feature is both for admin and user. The admin can see the water monitoring process (water level \& usage), can ON/OFF the water pump and the solenoid valve. And the user can see their water usage. The screenshots of the application for login, user add and account create has been shown in Fig. 6. (a); (b); (c) respectively.

\subsubsection{Water Management Interface}

In WMS the water management system can be done from the application using some interfaces. Fig. 7. (a) Shows a water pump with $1 \%$ full of water. This is a water tank of a building. Here the maximum limit of water is estimated 1000 and minimum limit is estimated 200. When water of this pump will reach the minimum rate the motor will turn ON and motor will turn OFF when it will reach the maximum rate.
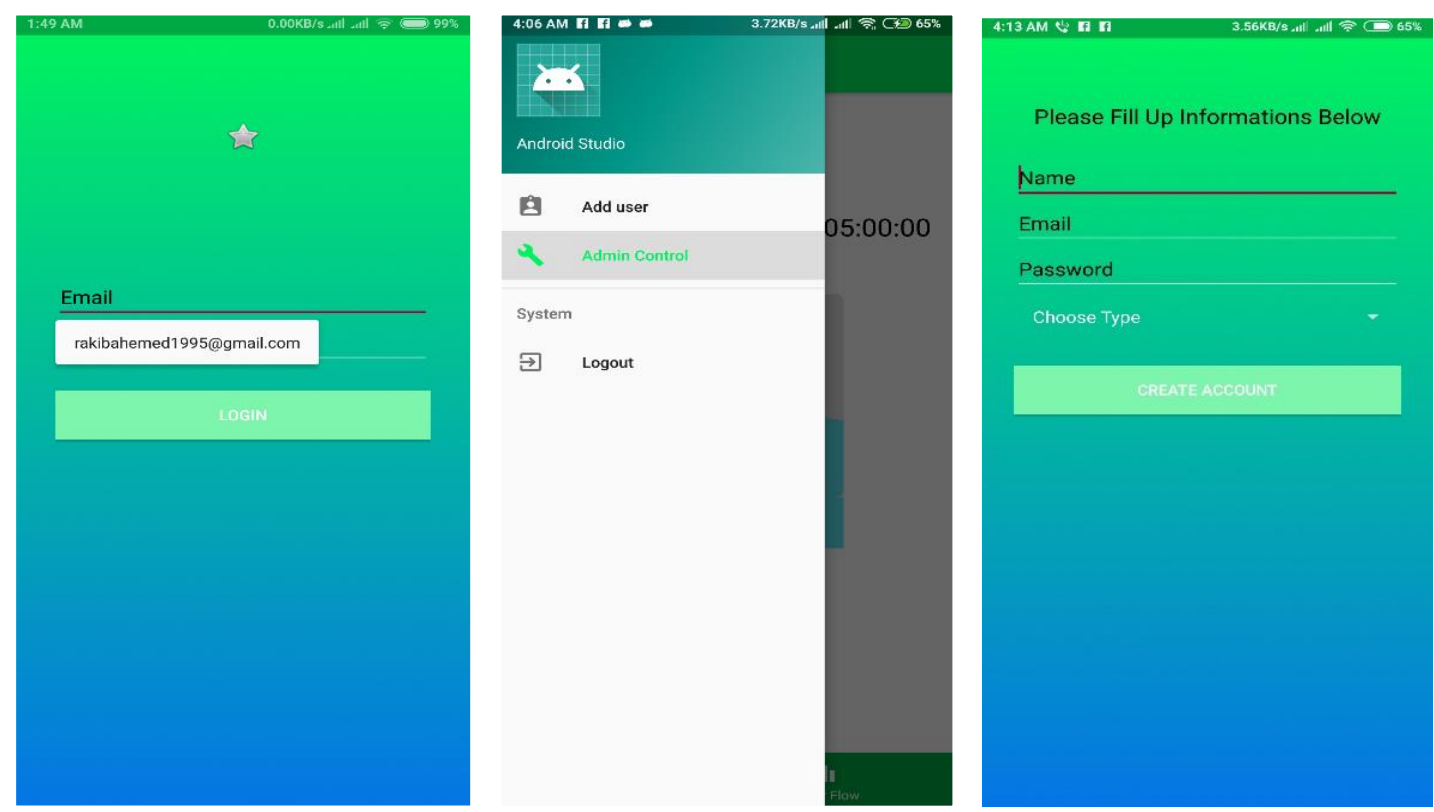

Fig.6. (a) User/Admin Login; (b) Adding User; (c) Account Create 

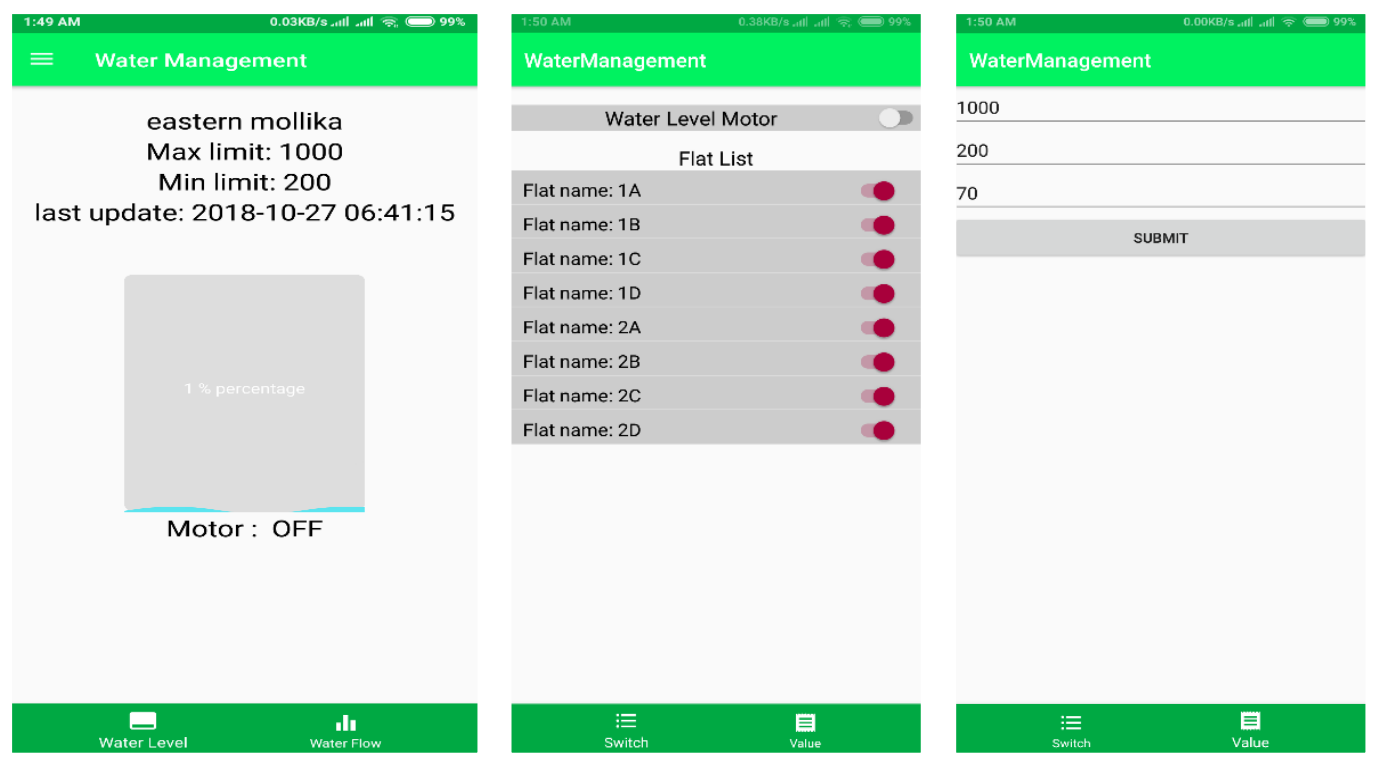

Fig.7. (a) Water Level and Flow; (b) Controlling Water Motor and Flow; (c) Water Usage

In Fig. 7. (b) It shows that admin can control the water flow and motor by switching ON/OFF. The admin can also cut-off water supply for a specific flat. Fig. 7. (c) Shows that the admin can also define the maximum and minimum amount of water in the tank. And also can define how much water can be used per user for a month.

\section{Discussion and Future Work}

This section discusses the benefit of the system and also indicates the limitations. This section will also give a direction to future scope of work.

\subsection{Benefits}

i. WMS can avoid wastage of water.

ii. In winter this system can supply hot water.

iii. The monitoring system of WMS can be used to make a monthly survey.

iv. Remotely the system can control the water pump.

v. The system can ON/OFF the water pump and water heater automatically.

vi. The user can be notified of their water usage through SMS.

vii. It is automatic and hence time consuming.

\subsection{Limitations}

i. WMS can be slow for dependency in a single microcontroller.

ii. Communication of WMS system is depended on a single server which is depended on high speed internet. If the internet becomes slow the communication will also be slow.

iii. There is no water-cooling process in this system. 


\subsection{Future Work}

The scope of this work is to overcome the above mentioned limitations. In future this system will add billing system for user. And also add water cooling system for better performance.

\section{Conclusion}

Water Management System (WMS) is an automated system for water to make daily life easy and comfortable through the use of mobile application. WMS is providing a system which can observe water tank and take action if water surface is high or low, it can automatically turn ON/OFF motor and also if any user wants to change water temperature then he/she can also do it. By using mobile messaging user get notifications before cut off his/her line and also show how much water he/she already used.

\section{References}

[1] Mazharul Islam Nayeem, Mahfida Amjad, "Water Automation for Water Pump Controller using Android Application - Review," International Journal of Computer Applications 182(29):34-38, November 2018.

[2] M. M. Raykar, Parijata Vinod, Parinita Vinod, Preethi K. M, L. Jain, "Automated Water Billing with Detection and Control of Water Leakage using Flow Conservation," International Journal of Engineering Development and Research, vol. 3, issue 2, pp. 285-287, 2015.

[3] S. Gowri, P. Pranathi, K. Sravya, "Automated Water Tank Overflow Control Unit Integrated with Mobile Application," International Journal on Information Sciences and Computing, vol. 9, no. 2, pp. 10-12, 2015.

[4] Jia Uddin, S. M. Taslim Reza, Q. Newaz, Jamal Uddin, T. Islam, J. M. Kim, “Automated Irrigation System using Solar Power," in Proc. International Conference on Electrical and Computer Engineering, 2012, pp. 228-231.

[5] Cristina Turcu, Cornel Turcu, Vasile Gaitan, "An Internet of Things Oriented Approach for Water Utility Monitoring and Control," Advances in Computer Science, WSEAS Conference, 2012, ISBN: 978-1-61804-126-5.

[6] Pragati Damor, Kirtikumar J Sharma, "IoT based Water Monitoring System: A Review," International Journal of Advance Engineering and Research Development, Volume 4, Issue 6, June -2017.

[7] Priya J, Sailusha Chekuri, "Water Level Monitoring System Using IoT,” International Research Journal of Engineering and Technology (IRJET), Volume: 04 Issue: 12, Dec-2017.

[8] Ayob Johari, Mohd Helmy Abd Wahab, Nur Suryani Abdul Latif, M. Erdi Ayob, M. Izwan Ayob, M. Afif Ayob, Mohd Norzali Haji Mohd, "Tank Water Level Monitoring System using GSM Network," International Journal of Computer Science and Information Technologies (IJCSIT), Vol. 2 (3) , 2011, 1114-1120.

[9] Souvik Paul, Mousumi Das, Anik Sau, Soumyadeep Patra, “Android Based Smart Water Pump Controller With Water Level Detection Technique", International Journal of Advanced Research in Computer and Communication Engineering Vol. 4, Issue 12, December 2015.

[10] S. S. Patil, V. D. Nikam, "Automation in Farming using Android Application," in Proc. International Conference on Recent Innovations in Engineering and Management, 2016, pp. 572-576.

[11] A. Nikam, N. Warhade, R. Dhawale, S. Prabhu, G. Deshmukh, "Fully Automated System for Monitoring Water Usage using SMS and Android Application," International Research Journal of Engineering and Technology, vol. 4, issue 5, pp. 2548-2551, 2017.

[12] P. P. Karande, P. N. Sawardekar, P. B. Patil, Prof. Z. J. Tamboli, "Study of Arduino for Irrigation Based 
Control using Android App," International Journal of Advanced Research in Computer Engineering \& Technology, vol. 6, issue. 1, pp. 46-49, 2017.

[13] A.N.Prasad, K. A. Mamun, F. R. Islam, H. Haqva, "Smart Water Quality Monitoring System," 2nd IEEE Asia Pacific World Congress on Computer Science and Engineering, DOI: 10.1109/APWCCSE.2015.7476234, December, 2015.

[14] Sajith Saseendran, V. Nithya, "Automated Water Usage Monitoring System," International Conference on Communication and Signal Processing (ICCSP), 2016.

[15] Soundarya Pappu, Prathyusha Vudatha and Niharika.A.V, Karthick.T and Suresh Sankaranarayanan, "Intelligent IoT Based Water Quality Monitoring System," International Journal of Applied Engineering Research, ISSN 0973-4562, Volume 12, Number 16, pp. 5447-5454, 2017.

\section{Authors' Profiles}

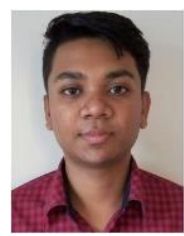

Rakib Ahemed was born in 1995 in Bangladesh. He has completed his Higher Secondary Certification in 2013 from Govt. Yasin College. He is a final year student of B.Sc. in Computer Science and Engineering of Stamford University Bangladesh. Now, he is doing his thesis on IoT based Automated System.

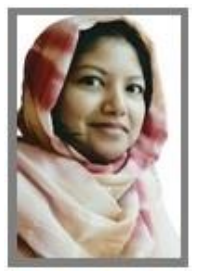

Mahfida Amjad was born in 1985 in Dhaka, Bangladesh. She has completed her Master degree in Information Technology from Institute of Information Technology from University of Dhaka in 2009. And she completed B.Sc. in Computer Science \& Engineering from Manarat International University in 2007.

She is a faculty member of Computer Science and Engineering (CSE) Department of Stamford University Bangladesh. She has devoted herself in teaching profession since 2012. Her research area is wireless ad hoc network, deep learning, IoT based automation.

How to cite this paper: Rakib Ahemed, Mahfida Amjad,"Automated Water Managemenrt System (WMS)", International Journal of Education and Management Engineering(IJEME), Vol.9, No.3, pp.27-36, 2019.DOI: 10.5815/ijeme.2019.03.03 